\title{
As condições históricas para a existência da qualidade educacional constatada pelas aualiações em larga escala
}

\author{
Historical conditions for the existence of the educational quality \\ verified by the large-scale assessments
}

\section{Las condiciones históricas para la existencia de la calidad educacional constatada por la evaluación en larga escala}

\author{
Jarbas Dametto' \\ Universidade de Passo Fundo (UPF), Professor e Pesquisador do Programa de Pós-Graduação \\ em Envelhecimento Humano \\ Rosimar Serena Siqueira Esquinsani ${ }^{2}$ \\ Universidade de Passo Fundo (UPF), Professora e Pesquisadora do Programa de Pós- \\ Graduação em Educação; Pesquisadora Pq/CNPq
}

Resumo: Partindo da centralidade das avaliações em larga escala nas políticas educacionais dirigidas à Educação Básica no Brasil, no presente artigo busca-se apresentar o arranjo político-discursivo que sustenta a aparição da "qualidade educacional" enquanto objeto apreensível por meio das avaliações padronizadas de redes de ensino. Sustentando o objetivo de esmiuçar as afinidades existentes entre um discurso poderoso na agenda educacional: a qualidade educacional, embasada nas avaliações em larga escala dado que, possivelmente, seja nessa coexistência que o objeto qualidade educacional, positivado por intermédio das avaliações, emerge enquanto objeto discursivamente possível e politicamente pertinente. Pautados na metodologia da pesquisa bibliográfica e revisão de literatura, no texto utiliza-se uma abordagem pós-estruturalista amparada nos escritos de Michel Foucault, dirigida ao discurso oficial e aos enunciados acadêmicos, na busca de historicizar o presente, elucidando as ancoragens epistêmicas e políticas que inscrevem o objeto "qualidade educacional" atualmente, em outros termos, apresentar os dispositivos que fazem o discurso contemporâneo da qualidade ser possível e politicamente incisivo. Enunciados, ou mesmo objetos do discurso, instituem campos de batalha, no qual forças são taticamente ordenadas na luta pela imposição do sentido. Conclui-se que,

Doutor e Mestre em Educação pela Universidade de Passo Fundo.

Doutora em Educação pela Universidade do Vale do Rio dos Sinos; Mestre em Educação pela Universidade de Passo Fundo. 
nessa esteira o discurso oficial da qualidade comporta um viés político evidente, ofuscado por uma pretensa objetividade, operada por rituais de veridicção específicos, como a avaliação externa em larga escala. A fabricação do objeto qualidade educacional enquanto performance em testes padronizados, remete ao campo interdiscursivo, cujos enunciados proporcionam a ele pontos de ancoragem e minimizam ou ofuscam suas inconsistências.

Palavras-chave: Educação básica. Qualidade educacional. Avaliações em larga escala.

Abstract: Based on the centrality of large-scale evaluations of educational policies aimed at basic education in Brazil, the article seeks to present the political-discursive arrangement that underpins the emergence of "educational quality" as an object apprehensible through standardized assessments of educational networks. Sustaining the objective of scrutinizing the existing affinities between a powerful discourse in the educational agenda: the educational quality, based on the large-scale evaluations given that it is possibly in this coexistence that the object of educational quality, positivized through evaluations, emerges as a discursively possible object and politically relevant. Based on the methodology of bibliographical research and literature review, the text uses a poststructuralist approach based on the writings of Michel Foucault, directed to the official discourse and to the academic statements, in the search of historicizing the present, elucidating the epistemic and political anchorages that inscribe the object "educational quality" currently, in other words, present the devices that make the contemporary discourse of quality possible and politically incisive. Statements, or even objects of discourse, institute battlefields, in which forces are tactically ordered in the struggle for the imposition of meaning. It concludes that, in this vein, the official quality discourse entails a clear political bias, overshadowed by a pretended objectivity, operated by specific verdict rituals, such as large-scale external evaluation. The fabrication of the object educational quality as performance in standardized tests, refers to the interdiscursive field, whose statements provide it with anchor points and minimize or obfuscate its inconsistencies.

Keywords: Basic education. Educational quality. Large-scale assessments.

Resumen: A partir de la centralidad de las evaluaciones a gran escala en las políticas educativas dirigidas a la Educación Básica en Brasil, el artículo busca 
presentar el arreglo político-discursivo que da sustentación a la aparición de la "calidad educativa" como objeto aprehensible a través de las evaluaciones estandarizadas de redes de enseñanza. Sosteniendo el objetivo de borrar las afinidades existentes entre un discurso poderoso en la agenda educativa: la calidad educativa, basada en las evaluaciones a gran escala, dado que, posiblemente, sea en esa coexistencia que el objeto calidad educativa, positivado a través de las evaluaciones, emerge como objeto discursivamente posible y políticamente pertinente. El texto utiliza un enfoque post-estructuralista amparado en los escritos de Michel Foucault, dirigida al discurso oficial ya los enunciados académicos, en la búsqueda de historizar el presente, elucidando los anclajes epistémicos y políticas que inscriben el objeto "calidad educativa" actualmente, en otros términos, presentar los dispositivos que hacen que el discurso contemporáneo de la calidad sea posible y políticamente incisivo. Enunciados, o incluso objetos del discurso, instituyen campos de batalla, en el cual fuerzas son tácticamente ordenadas en la lucha por la imposición del sentido. Concluye que, en esta estera el discurso oficial de la calidad comporta un sesgo político evidente, ofuscado por una pretendida objetividad, operada por rituales de veridicción específicos, como la evaluación externa a gran escala. La fabricación del objeto calidad educativa como desempeño en pruebas estandarizadas, remite al campo interdiscursivo, cuyos enunciados le proporcionan puntos de anclaje y minimizan u ofuscan sus inconsistencias.

Palabras clave: Educación básica. Calidad educativa. Evaluaciones en larga escala.

\section{INTRODUÇÃO}

As coisas do mundo não estão à espera de um discurso que as nomeie, que dê a elas sentido, ao contrário, é no discurso que elas ganham sua existência e podem vir aos olhos humanos (FOUCAULT, 2008a). Por sua vez, os discursos não habitam espaços alheios ao social, não haveria uma existência a-histórica do fenômeno discursivo, nem este emergiria isoladamente, como um fato desprovido de conexões. Como pontua Fischer (2001), sempre há relações de interdiscursividade nas práticas discursivas, bem como a imbricação entre 
discursos e práticas na construção do saber acerca das coisas e nas ações políticas nelas envolvidas. Enunciados, ou mesmo objetos do discurso, instituem campos de batalha, no qual forças são taticamente ordenadas na luta pela imposição do sentido.

Partindo dessas premissas foucaultianas, que pressupõem relações historicamente situadas entre campos discursivos e enunciados diversos, neste trabalho pretende-se esmiuçar as afinidades existentes entre um discurso poderoso da contemporaneidade, aquele da "qualidade educacional", atualmente ancorado nas avaliações em larga escala, e outros discursos a ele contemporâneos, dado que, possivelmente, seja nessa coexistência que o objeto qualidade educacional, positivado por meio das avaliações, emerge enquanto objeto discursivamente possível e politicamente pertinente.

Com o declarado intento de fragilizar o discurso da qualidade educacional oficialmente sustentado, pretende-se aqui retomar algumas noções ou conceitos que se relacionam, temporal ou dinamicamente, à noção de qualidade educacional em voga na atualidade. Dentro dessas noções, salientam-se alguns tópicos aos quais se dará maior atenção, considerando que contemplam elementos que embasam a atual onipresença das avaliações educacionais externas, a saber, os seguintes fenômenos: o gerencialismo ou lógica de mercado aplicada à educação, a performatividade, a cultura avaliativa, a accountability ou responsabilização. Com tal apreciação, pretendese discorrer sobre a participação desses fenômenos na gênese da qualidade alicerçada em avaliações em larga escala, bem como em seu derivado prático: a construção de um ethos educacional norteado por princípios performáticos.

\section{A REESTRUTURAÇÃO DO ESTADO E SEUS REFLEXOS SOBRE A EDUCAÇÃO}

Como propõe Shiroma (2009), haveria desde a década de 1990, período de reestruturação do Estado provocada pelas crises do capitalismo vividas nas décadas de 1970 e 1980 e pela opção neoliberal então adotada 
como perspectiva político-econômica em diversos países, uma presença incisiva de discursos oriundos de órgãos financeiros internacionais sobre os modos de gerir a educação. Tais "recomendações" atingiriam a carreira docente, a formação de professores e, por vias indiretas, a própria prática pedagógica. A referida década marcaria a derrocada dos modelos educacionais amparados pelo modelo de Estado de Bem-estar Social, lançando-os em modalidades de gestão que não os resguardavam de ajustes que desconsideravam suas especificidades,

[...] a década de 1990 foi marcada por profundas mudanças nas formas de organização e gestão do Estado e, consequentemente, no âmbito das políticas educacionais. A maioria dos países realizou reformas do Estado em função dos novos cenários econômicos, políticos e culturais que se desenhavam com os processos de reestruturação produtiva e mundialização do capital. Tais reformas repercutiram efetivamente no campo das políticas educacionais e, desse modo, os anos de 1990 foram marcados por grandes mudanças nas políticas nacionais para a educação e, em consonância a essas mudanças, por forte agenda internacional balizada por conferências mundiais, acordos, compromissos multilaterais, dentre outros. (DOURADO; OLIVEIRA; SANTOS, 2007, p. 15).

"Fazer mais com menos" se tornou uma diretriz óbvia no setor educacional, que historicamente demanda grandes investimentos financeiros, bem como se evidenciou a necessidade de explicitar publicamente os resultados de tal empreendimento, por meio de sistemas de controle que tinham, como uma opção, as avaliações em larga escala, pensadas como uma prática voltada a alunos e possivelmente também a professores. Como propõe Afonso (2001, p. 24) tais reformas estatais possuem "[...] uma amplitude muito maior do que aquela que pode estar subentendida quando se fala em simples modernização da administração." Ela implica a transição de um Estado provedor para um Estado cujas incumbências se centram no controle e avaliação dos serviços de caráter público.

As avaliações externas em larga escala ocupam lugar de destaque na composição de uma Educação voltada aos resultados, incitada por órgãos internacionais e alardeada pela mídia de massa. Como aponta Ball (2005, 
p. 544), daí decorre a instituição de uma cultura performática a partir da “[...] construção e publicação de informações e de indicadores, além de outras realizações e materiais institucionais de caráter promocional, como mecanismos para estimular, julgar e comparar profissionais em termos de resultados: a tendência para nomear, diferenciar e classificar." Esse fenômeno estaria intimamente vinculado à transposição de parâmetros administrativos da esfera privada aos órgãos públicos, como as escolas, fenômeno denominado gerencialismo, observado mundialmente e atribuído ao ideário neoliberal.

A perspectiva gerencialista, compreendida como uma nova racionalidade de gestão pública, implicou mudanças importantes, tanto na estrutura da gestão estatal quanto nas concepções acerca do papel do Estado na sociedade. As crises econômicas das décadas finais do século XX marcaram a dissolução do consenso social que sustentou as propostas do Estado de Bem-estar Social, modelo que se mostrou eficaz nos países capitalistas após a Segunda Guerra Mundial. A partir da década de 1970, emergiram potentes críticas à ampla participação do Estado na economia e ao grande provimento de bens e serviços que então possuía, assim como aos custos que isso implicava. $\bigcirc$ modelo de burocracia weberiana, que buscava garantir a impessoalidade dos atos do Estado, também passou a ser visto como ineficiente, dado que estaria sufocando o dinamismo e a eficiência que o cenário econômico globalizado exigia, além de ser acusado de clientelismo e de priorizar os interesses próprios ao funcionalismo público e à classe política. Nota-se, então, que o ingresso do modelo privado na coisa pública ocorreu sob pressões econômicas (decorrentes das crises vividas a partir da década de 1970 e pela ampliação dos custos de um Estado burocratizado e que abarcava, supostamente, demasiadas funções econômicas e sociais), bem como em decorrência da pressão teórica e ideológica que evidenciou as mazelas do modelo anterior, bem como apresentou o modelo privado como a via possível para o enfrentamento da nova realidade (ABRUCIO, 1997).

Em poucas palavras, Ramos (2016, p. 547) resume essa perspectiva de gestão: 
Sob a genérica denominação "Nova Gestão Pública", o modelo gerencialista de gestão objetiva agregar princípios, valores e estratégias provenientes da administração privada (racionalização de tarefas; separação entre os níveis estratégico e operacional de decisão e ação; gestão por objetivos/resultados; remuneração por desempenho, etc.) à gestão pública.

Entretanto, como aponta Abrucio (1997), o gerencialismo não se mostra um modelo estático ou um novo paradigma que suplanta o anterior, pelo contrário, trata-se de uma perspectiva em aberto, que interage com as críticas a ela propostas, gerando novos arranjos, técnicas e conceitos. As avaliações educacionais em larga escala que este estudo problematiza, bem como a accountabillity, que adiante será abordada, são parte da ferramentaria e das premissas contemporâneas desse modo de gerir o setor público, que remetem a formas não burocráticas de controle social sobre a ação do Estado.

Como desdobramento prático (e potencialmente pernicioso) dessa racionalidade na gestão pública, tem-se "[...] o enxugamento da atuação do Estado notadamente no campo social, tendo como características básicas desse processo a criação de políticas, que caminham no sentido da descentralização [...] de suas atribuições, para a sociedade em geral ou para setores específicos dela." (RAMOS, 2016, p. 548). Além disso, a gestão das relações de trabalho no setor público acabam por ganhar entonações da experiência da esfera produtiva.

Sobre esse último tópico, Ball (2005, p. 545) propõe que o modelo gerencialista aplicado às instituições acaba por "incutir performatividade na alma do trabalhador" produzindo efeitos subjetivos consideráveis, como a construção de novos parâmetros de autoavaliação, mudanças de objetivos e construção de novas práticas. Nota-se, nesse fenômeno, que não se trata propriamente de uma imposição ao campo educacional, mas da cooptação de desejos a ele legítimos, por uma lógica alheia à Educação e, até então, ao Setor Público, o que acaba por repercutir sobre as formas de vivenciar a experiência educacional. Refletindo sobre os desdobramentos de tal fenômeno na docência, Shiroma (2009, p. 384-385) pontua que 
A categoria docente vive tempos de tensões e encruzilhadas à medida que assiste a suas demandas históricas serem incorporadas por projetos de educação inspirados em outras referências, visando a objetivos distintos e produzindo efeitos deletérios à educação e aos professores [...] Nesse complexo processo de ressignificações, o familiar nos causa estranheza, quando vemos demandas da categoria ou demandas populares serem utilizadas para arrebanhar consensos e adesões aos projetos internacionais para a educação. Cumpre observar que se trata de uma incorporação das bandeiras do movimento docente, mas subordinada a outra lógica, na qual fins viraram meios de se chegar a resultados, sobre os quais não há acordo.

As últimas décadas vêm demonstrando que o discurso gerencialista não é uma opção partidária, algo que remeta a um grupo delimitado de políticos, gestores ou intelectuais. Suas premissas e práticas avançam, tanto nas mãos de "neoliberais" quanto pelos esforços de quem se proclama opositor desse modelo, sendo que resistências efetivas existem, mas emergem em movimentos isolados e não como mobilizações políticas amplas. Do mesmo modo, alguns de seus aparatos, como as avaliações em larga escala, também se replicam sem grandes resistências em diversos contextos político-econômicos.

Nas últimas duas décadas e meia, pelo menos nos países capitalistas democráticos ocidentais, as políticas de avaliação foram ganhando um estatuto relativamente indiferente às concepções político-ideológicas que lhe subjazem e foram, também, alcançando uma certa imunidade ou indiferença às realidades (nacionais, regionais, sociais, culturais...) em que os diferentes dispositivos avaliativos se têm instalado e desenvolvido. É, aliás, esta aparente consensualidade que vem ampliando a eficácia legitimadora da avaliação e tornando mais difícil desmontar e pôr em questão a sua aparente e pretendida neutralidade. (AFONSO, 2007, p. 17).

Como uma verdade, o gerencialismo e seus recursos de gestão, avançam com nítida naturalidade e unanimidade, vencendo as frágeis oposições que a ele se levantam. $\bigcirc$ mercado, com suas práticas, consolidase, por excelência, como o "local de veridicção" (FOUCAULT, 2008b) da contemporaneidade. 
Foucault (2008b) propõe que o mercado, dentro do ideário liberal, proposto a partir do Século XVIII, institui-se como um local de veridição, princípio revisitado e intensificado pelo neoliberalismo. Em uma concepção inicial, o mercado, quando submetido à mínima intervenção do Estado, deixaria agir a "natureza" do funcionamento econômico, fazendo emergir o preço "verdadeiro" daquilo que é objeto de troca, "[...] o mercado deve ser revelador de algo que é como uma verdade." (FOUCAULT, 2008b, p. 44). As respostas do mercado, a partir daí, atestarão a veracidade e definirão o correto e o incorreto das práticas governamentais. A economia política não somente propôs teorias, mas também "[...] indicou onde o governo deveria buscar o princípio de verdade de sua própria prática governamental" (FOUCAULT, 2008b, p. 45), a saber, no mercado.

Essa hegemonia do modelo de mercado excede os limites das formas de gerir o trabalho, e as instituições educacionais inscrevem-se efetivamente como uma cultura, que inclui crenças, discursos, práticas e objetos fetichizados (DAMETTO; ESQUINSANI, 2015). A seguir, discorre-se mais extensamente sobre a cultura performática e sobre o modo como os índices numéricos se convertem no eixo central desse processo.

\section{A PERFORMATIUIDADE E O RANQUEAMENTO: NOUOS MOTIUOS PARA ENSINAR}

Performance é um conceito que porta vários significados, contemplando áreas e ideias distintas. Dentre as concepções que se vinculam ao termo performance, podemos relacionar a sua inscrição no campo da arte, que contempla uma potente e inquietante forma de expressão artística híbrida, a qual se posiciona nas fronteiras entre o teatro, a dança, o ritual, as artes visuais, a experiência e a intervenção, em um processo criativo que, por vezes, convida o expectador a participar de seu enquadre. Nesse contexto, o artista ganha o atributo de performer, sujeito que faz de si mesmo elemento de sua expressão artística. $\bigcirc$ termo também se situa dentro do pensamento antropológico e 
sociológico, ao descrever a dimensão dos atos nas interações sociais, o "como fazem", e não somente os motivos pelos quais o fazem, análise que pode se debruçar nos corpos e na linguagem, tomando essa última como um fenômeno de realização e não apenas de representação. Por fim, pode-se conceber a performance como um meio de regulação, uma forma de apresentação de desempenhos que fomenta a performatividade, que seria um modo um tanto parcial de desenvolver um juízo de valor acerca das práticas e das instituições submetidas a avaliações padronizadas (ICLE, 2010).

É dentro do último sentido mencionado que se situa a presente análise: a performance e a performatividade como um conjunto de fenômenos relacionados ao posicionamento de cada elemento em um entorno social, vinculados ao que se faz visível e comparável de uma experiência ou realidade e ao que disso se traduz em discurso. Grosso modo, a performatividade se configura como um fenômeno da ordem do poder, na qual o desempenho de indivíduos e instituições é posto à luz por meio de técnicas específicas que os enredam política e discursivamente, incitando movimentos de adesão ou resistência nos sujeitos envolvidos (DAMETTO; ESQUINSANI, 2015).

Tal leitura acerca da performatividade foi proposta primeiramente por Lyotard, momento no qual o autor, nos fins da década de 1970, propõe que os critérios de legitimação do conhecimento e da ação nas sociedades pós-industriais passaram a ser pautados pela relação entre a entrada e a saída em um sistema, o melhor desempenho/produtividade entre o input e o output, aquilo que alimenta o sistema e aquilo que o sistema devolve em termos de resultados (LYOTARD, 2000; BALL, 2010). A performance assim compreendida,

[...] implica julgamento, comparação e exposição, tomados respectivamente como formas de controle, de atrito e de mudança. Performances - de sujeitos individuais ou organizações - servem como medidas de produtividade ou resultados, como formas de apresentação da qualidade ou momentos de promoção ou inspeção. Elas significam, encapsulando ou representando um valor, a qualidade ou a valia de um indivíduo ou de uma organização dentro de um campo de julgamento. (BALL, 2010, p. 38). 
A mensuração acerca do desempenho enquanto crivo de legitimação de uma prática se vê formalizada nas avaliações e inspeções padronizadas voltadas à educação em massa. Criar indicadores, métodos de avaliação, relatórios periódicos, bem como "melhorar" os índices de qualidade a cada nova coleta de informações, têm sido empreendimentos para os quais governos estão dedicando especial atenção e volumosos investimentos financeiros. $\grave{A}$ semelhança da empresa privada, o setor público passou a buscar visibilidade e legitimidade por intermédio de marketing, sendo este fundamentado em índices de eficácia e eficiência, bem como por meio de demonstrativos numéricos de progresso e crescimento. Nesses termos,

[...] a performatividade funciona para empurrar as instituições do setor público à maior convergência com o setor privado. Paradoxalmente, a performatividade requer das instituições do setor público tanta atenção às mudanças simbólicas e às manipulações quanto ela exige das mudanças reais. Ela encoraja as instituições a se preocuparem cada vez mais com seu estilo, sua imagem, sua semiótica, com a maneira como apresentam as coisas mais do que como as fazem funcionar. De fato, o projeto de transparência por meio da performatividade produz maior complexidade e opacidade, uma vez que as organizações do setor público gastam tempo, dinheiro e energia com gestão das aparências, marketing e promoção. (BALL, 2004, p. $1117-1118)$.

Um dos desdobramentos mais gritantes da performatividade é - ranqueamento de instituições que não necessariamente estabelecem competição. A emergência de rankings pode ser tomada como um dos fenômenos que mais mobilizaram o campo educacional nos últimos anos, embora esse desdobramento decorrente de avaliações externas não esteja previsto nas legislações sobre o tema. Tal questão, cujas dimensões são mundiais, configura uma tendência em diversos setores antes não submetidos a esse tipo de tratamento e análise: para além da Educação, também a Ciência, a Saúde, a Segurança Pública, entre outros recortes da experiência social, são objeto de ranqueamentos, que além de fomentarem uma inoportuna competição, propõem juízos de valor sobre as condições, populações ou instituições avaliadas. 
○ termo ranking é comumente utilizado para descrever uma relação de posicionamento de um elemento perante os demais, baseado em escores ou dados estatísticos. Trata-se de uma ferramenta de comparação amplamente utilizada, por exemplo, nos esportes e nos negócios, contextos em que a finalidade é, evidentemente, a competição. $\bigcirc$ ranqueamento expõe de modo acentuado os maiores e os menores, bem como os melhores e os piores, os "modelos" e os "párias" (DAMETTO; ESQUINSANI, 2015).

Para além de sua forma pretensamente objetiva, é notável o poder de atração causado por tais recursos em uma dimensão propriamente subjetiva: a curiosidade que provocam e o poder de posicionamento que comportam, permitindo julgamentos rápidos e "fundamentados" sobre os mais diversos assuntos. Tal fundamentação viria, necessariamente, da suposta credibilidade do método utilizado e das agências avaliadoras, condições que imputariam aos dados obtidos o status de verdade.

Para a compreensão dessas dimensões no ranqueamento educacional, pode-se recorrer à análise realizada por Andrade (201 1, p. 326-327) acerca dos fundamentos teórico-metodológicos utilizados na construção dos rankings educacionais:

\begin{abstract}
A educação pode ser entendida como um serviço que transforma insumos em produtos. Ela pode ser representada por uma função de produção, que mostra a relação existente entre esses insumos e produtos e, adicionalmente, corresponde também ao máximo de produção que pode ser alcançado dados os insumos utilizados.

[...]

Uma versão alternativa deste modelo é comumente utilizada. Ao invés de usar o valor do produto num determinado ponto no tempo, o foco da análise é no valor adicionado. Ou seja, quanto que ocorreu de ganho no produto de um período para outro.
\end{abstract}

A escola, como anteriormente exposto, é tomada como um lugar que produz ou que agrega valor por meio da quantidade e qualidade de insumos aplicados e da excelência dos processos desenvolvidos em seu interior. Tal 
afirmação explicita a raiz epistemológica do ranqueamento educacional: são práticas amparadas em um saber derivado do campo econômico/produtivo, e é nesse mesmo campo que ele busca ser compreendido e gerar seus efeitos.

Andrade (2011) aponta alguns dos problemas metodológicos do ranqueamento, sendo o mais considerável o fato de que ele se sustenta em alguns pressupostos contestáveis, como, por exemplo, que a quantidade de insumos investidos do processo necessariamente aumenta a qualidade, o que pode não se confirmar na prática ou mesmo ser refutado por outro viés de avaliação. Bem como se constroem rankings mediante a coleta de dados subjetivos, de pareceres dos experts e do público amplo envolvido na instituição, o que revela um apanhado de pontos de vista que não necessariamente refletem qualidade - antes, são uma pesquisa de imagem e de opinião (caso bastante comum em ranqueamentos de instituições de ensino superior). ${ }^{3}$

Embora o ranking educacional comporte essas fragilidades, ou seja, admita uma base metodológica suspeita ou francamente contestável, bem como seja uma prática que advém de um campo epistemológico alheio ao educacional, é inegável que ele vem causando "efeitos de verdade", conduzindo as ações dos sujeitos envolvidos. Andrade (2011) salienta que tais rankings, elaborados pelos governos, mas incluindo também aqueles organizados pelo setor privado, geram consequências nas escolhas da futura "clientela" da instituição de ensino, bem como nos "consumidores finais" dos "produtos" da escola: o mercado de trabalho que emprega a mão de obra formada nas instituições avaliadas.

Reafirmando a função do ranqueamento, tem-se que:

$\bigcirc$ objetivo é fornecer informações sobre a qualidade das instituições para os diferentes stakeholders. Elas podem auxiliar pais/estudantes na escolha de onde estudar, empregadores na contratação de novos funcionários, governos nos seus programas voltados para a melhoria da qualidade da educação e o próprio MEC no seu trabalho

\footnotetext{
3 Um exemplo nacional desse modo de valoração e ranqueamento é o Guia do estudante realizado pela Editora Abril, que consiste em " uma pesquisa de opinião feita, basicamente, com professores e coordenadores de curso. Eles emitem conceitos que permitem classificar os cursos em bons (três estrelas), muito bons (quatro estrelas) e excelentes (cinco estrelas)." (GUIA DO ESTUDANTE, 2016).
} 
de regulação do setor educacional. (ANDRADE, 2011, p. 324).

Também cabe pontuar que a ojeriza contemporânea aos grandes textos e às explicações detalhadas, observada no grande público, bem como a gestão governamental baseada em dados estatísticos e indicadores numéricos fazem do ranking um instrumento poderoso na construção de uma leitura da realidade e de um posicionamento político diante dela. Os números, quando retirados de seu contexto de origem e ignorando os meios pelos quais foram obtidos, revestem-se de uma perigosa naturalidade. Como verdades, eles "aderem" à instituição as pessoas que a ela se vinculam (DAMETTO; ESQUINSANI, 2015). Nesse processo, o número acaba retroalimentando a virtude ou a fraqueza da instituição avaliada, cooptando ou repelindo pessoas, direcionando ou desviando investimentos, reforçando ou denegrindo o apreço social da instituição avaliada, enfim, tendo um efeito econômico, político e moral considerável (RAVICH, 2011 ).

Atrelados a uma cultura performática, universidades, escolas, alunos e professores não deixaram de se posicionar perante esse panorama, empenhando-se individual e coletivamente, de modo tímido ou ostensivo, na busca por um olhar desejante do "grande outro" - o mercado. Rosistolato, Prado e Fernández (2014, p. 78), pesquisando os efeitos das avaliações no âmbito da gestão interna de escolas cariocas, constataram alguns desdobramentos dessa experiência:

[...] há uma tendência à utilização dos dados delas resultantes como norteadores das práticas de gestão, mesmo com o desconhecimento técnico das avaliações. Foi possível perceber um "efeito dominó". Trata-se de um conjunto de cobranças sucessivas aos agentes de acordo com sua posição na hierarquia da gestão, que induz estratégias para melhorar o desempenho institucional, assim como "jeitinhos" e estratagemas orientados pela expectativa de aumentar os índices das escolas.

Considerações dessa ordem, confirmam que, na esteira das premissas do mercado, a experiência educacional (mas não somente ela) passa a ser 
pautada pela inautenticidade, por uma cisão entre as convicções pessoais e a prática exigida e valorizada. Ball (2010) propõe que a performatividade e a responsabilização, reflexos de uma privatização (por vezes não consumada em termos econômicos, mas evidente em sua dimensão ideológica e funcional), que abarcou diversos setores da esfera pública, acarretam um processo de "fabricação" subjetiva, um exercício de autoenquadramento nas metas e nos padrões validados pelas avaliações externas, que subverte a autoimagem profissional e o sentido do próprio trabalho. Afirma o autor, que "[...] com efeito, nós nos criamos na medida da informação que construímos e transmitimos sobre nós mesmos. Nós nos articulamos dentro desses jogos representacionais de competição, intensificação e qualidade." (BALL, 2010, p. 38).

A cultura performática materializa-se em políticas meritocráticas, de valorização, remuneração e premiação por resultados, que estabelecem e formalizam a pressão por produtividade e concorrências intra einterinstitucionais. Formar alunos treinados como exímios respondedores de testes, em uma escola com dinâmicas pedagógicas típicas de cursos preparatórios para exames passa a ser, embora um contrassenso em termos pedagógicos, algo legitimado como uma "boa prática educacional" por meio da verdade exposta pelas avaliações e rankings educacionais (DAMETTO; ESQUINSANI, 2015). Como propõe Santos (2004, p. 1153), "[...] os alunos terminam, desde os primeiros anos da educação fundamental, por ser treinados para obter bons resultados nos testes em vez de serem educados no sentido amplo deste termo."

Outra tendência que pode ser observada é a padronização do ensino como reflexo direto da forma das avaliações externas, uma espécie de "aprisionamento curricular" em razão das matrizes de referência dos testes. Qualquer princípio de liberdade na produção e opção por conteúdos, formas e temáticas a serem estudadas é sufocado pelo referencial teórico básico das grandes avaliações padronizadas, principalmente aquelas que obtêm seus dados mediante testes de proficiência. Morris (2017) argumenta que, quando isso se desdobra em práticas escolares visando a melhores indicadores, ainda há certo estranhamento e crítica; entretanto uma plácida naturalidade ocorre quando isso é operado como política de Estado, aplicada a redes educacionais inteiras: 
Se os países fizerem isso e melhorarem seus resultados, entraremos em um sistema fechado e autorrealizável, no qual os países ensinam de acordo com os requisitos do exame, e melhores pontuações criam a ilusão de melhoria. Quando os professores o fazem, isso é denunciado como "ensinar para a prova" ou "manipular o sistema". Quando se trata de um esforço nacional, a prática é remodelada como "benchmarking global" ou "aprendizado com as melhores práticas internacionais". (MORRIS, 2017, p. 335).

Ravitch (2011), ao observar as consequências de reformas educacionais norte-americanas alicerçadas em pressupostos do mercado, empreendidas a partir da década de 1980, reporta que a testagem padronizada, quando utilizada como critério maior de validação de uma prática educacional, pode acarretar o empobrecimento do currículo e subverter os objetivos da educação, direcionando-os à mera conquista de índices numéricos e não a uma formação integral. Essa conversão ocorre diante da utilização dos indicadores de aproveitamento dos alunos como referencial para a responsabilização dos professores, e para que estes sejam, meritocraticamente, recompensados ou punidos. Tais para-efeitos das avaliações externas padronizadas são apresentados como fatos consumados em diversas experiências estadunidenses analisadas pela autora, apontando objetivamente para a precariedade de uma transposição dos moldes de gestão mercantis para a educação. Ravitch também atenta para o uso desses mecanismos de avaliação como forma de forçar a privatização da educação, vinculando, de modo simplista, os maus resultados à gestão pública das escolas, criando a relação, ideologicamente embasada, público $=$ precário versus privado $=$ eficiente.

Nesse cenário, "[...] os valores e incentivos das políticas de mercado legitimam e dão impulso a certos compromissos e ações - empreendimento, competição, excelência - ao mesmo tempo que inibem e deslegitimam outros - justiça social, equidade, tolerância." (BALL, 2004, p. 1122). Tal movimento, cabe afirmar, configura um sério risco aos princípios que deveriam pautar a educação de um contexto que almeja uma forma de vida democrática.

A cultura da performance, sustentada pelas avaliações em larga escala, há algum tempo vem batendo às portas da Educação Básica. Mesmo que 
com semblantes menos ostensivos do que aqueles já observados na Educação Superior, seus efeitos na mídia e no grande público já se fazem sentir, servindo de argumento para qualificação ou desqualificação de redes de ensino, escolas e sujeitos envolvidos, bem como ditando parâmetros sobre os rumos da educação a serem seguidos. As releituras midiáticas, bem como a apropriação destas pelo público, não podem ser tomadas como meros epifenômenos relativos à avaliação; pelo contrário, é nessa dimensão que se realiza grande parte dos efeitos práticos de ordem política e econômica, bem como no campo das escolhas e dos julgamentos, diante dos números resultantes de avaliações padronizadas (DAMETTO; ESQUINSANI, 2015).

Cabe pontuar que, para uma escola adentrar a "alta performance", ela deve ajustar-se a uma série de condições, que podem ser sintetizadas em um simples quesito: possuir um seleto grupo de alunos treinados para esse fim. Como observa Andrade (201 1, p. 341), o ranking pode vir em benefício daquelas escolas "[...] com menor preocupação em recuperar os alunos com maiores dificuldades de aprendizado em detrimento daquelas com políticas mais inclusivas. $\bigcirc$ problema é que estas últimas podem ser as mais eficientes na produção do serviço educacional." Ou seja, a "qualidade" captada pelas avaliações pode ser representativa de um arranjo favorável em termos de população atendida, condições socioeconômicas da população ou práticas pedagógicas alinhadas com um modo produtivista de conceber a educação, para não dizer, um efetivo treinamento para os testes.

\section{A CULTURA AUALIATIUA}

A performatividade extrapola os limites de uma demanda por constatar a performance de indivíduos, instituições ou governos pela via de avaliações de diversas naturezas; ela inscreve-se como um fenômeno cultural que institui novos parâmetros de apreciação da realidade e de inserção nela. Sua lógica pressupõe o engajamento dos sujeitos envolvidos e não a submissão destes a proposições arbitrárias (embora, em um momento de transição, isso 
possa ocorrer). É nesse engajamento que a cultura performática desdobra seus efeitos - impele à ação, visando contemplar os critérios valorativos por ela fomentados. Por vezes, tal fenômeno é apresentado como a construção de uma "cultura avaliativa", que implicaria a busca de "qualidade" na empreitada executada, mas com o deslocamento da atenção dada aos processos, para uma ênfase pontual sobre os resultados, em especial, aqueles mensuráveis.

Nota-se que o termo "cultura avaliativa" não possui, originalmente, uma conotação negativa. Como propõe Ravich (201 1), os processos avaliativos ostentam a promessa de que eles seriam capazes de melhorar, por si sós, as experiências educacionais para as quais se dirigem. Essa concepção positiva pode ser percebida em textos oficiais, como o que será mencionado a seguir, no qual a implementação de uma cultura avaliativa aparece como um objetivo a ser alcançado.

Monteiro e Fernandes (2012) propõe que o SAEB, após a Portaria n. 931 de 2005, por meio da Avaliação Nacional do Rendimento no Ensino Escolar (ANRESC), assume explicitamente a função de disseminador de uma "cultura avaliativa" na Educação brasileira, tomada nesse documento como um fator que possuiria o poder de fomentar a qualidade e a equidade educacional pelas vias do controle social de resultados. Nos termos do referido documento, tem-se:

$\S 2^{\circ}$ A Avaliação Nacional do Rendimento no Ensino Escolar - ANRESC tem os seguintes objetivos gerais:

a) avaliar a qualidade do ensino ministrado nas escolas, de forma que cada unidade escolar receba o resultado global;

b) contribuir para o desenvolvimento, em todos os níveis educativos, de uma cultura avaliativa que estimule a melhoria dos padrões de qualidade e equidade da educação brasileira e adequados controles sociais de seus resultados;

c) concorrer para a melhoria da qualidade de ensino, redução das desigualdades e a democratização da gestão do ensino público nos estabelecimentos oficiais, em consonância com as metas e políticas estabelecidas pelas diretrizes da educação nacional;

d) oportunizar informações sistemáticas sobre as unidades escolares. Tais informações serão úteis para a escolha dos gestores da rede a qual pertençam. (BRASIL, 2005, p. 17. grifo nosso). 
Monteiro e Fernandes aduzem, ainda, a esse respeito, que

[...] ao fazer opção pelo caminho da cultura avaliativa, terá de assumir as implicações anexas a essa opção. As buscas pela melhoria dos resultados nas avaliações podem trazer os efeitos desejados no que diz respeito a números. Cabe aqui, um questionamento: os números estatísticos melhores são sinais de uma educação eficiente e de qualidade? [...] A cultura avaliativa é um passo que o governo federal assumiu e com cujas consequências terá que arcar. (MONTEIRO; FERNANDES, 2012, p. 107).

Considerando a questão das avaliações em larga escala em estudos realizados no Reino Unido, contexto no qual tal cultura avançou antes do que na realidade brasileira, Ball (2005, p. 548) considera que “[...] a prática da sala de aula cada vez mais é 'remodelada' para responder às novas demandas externas. Os professores são 'pensados' e caracterizados de novas maneiras; cada vez mais são 'pensados' como técnicos em pedagogia." Percebe-se o efetivo engajamento comentado, mas este se atrela aos índices numéricos e não à suposta "qualidade" que eles poderiam estar representando. Efeitos correlatos já foram percebidos em estudos em municípios do Estado do Rio de Janeiro, incluindo importantes orientações no âmbito da gestão: "O que tem sido observado é que os municípios vão alterando as suas políticas, a partir das orientações e demandas emanadas dos órgãos nacionais, comprometendo políticas locais, definidas em períodos anteriores e a consolidação de propostas em andamento." (MONTEIRO; FERNANDES, 2012, p. 108).

Reafirmam os autores anteriormente citados que "atualmente, percebemos a consolidação da 'cultura avaliativa', evidenciando as inúmeras avaliações em larga escala, produzidas no país pela União, estados e até mesmo municípios" (MONTEIRO; FERNANDES, 2012, p. 1 10), e que seus efeitos também já se fazem sentir, com maior ou menor resistência dos envolvidos, em todos os recortes da experiência educacional.

Outro desdobramento potencialmente pernicioso dessa cultura é a inserção de seus resultados dentro de uma perspectiva mercadológica/ competitiva, pautada por uma lógica performática. Tais "competições" não são 
previstas legalmente nem tecnicamente na elaboração das avaliações nacionais, entretanto, em sua apropriação pelo público em geral, isso objetivamente ocorre, principalmente quando dados são veiculados midiaticamente, perdendo o caráter técnico e se tornando pequenos espetáculos para o deleite ou horror do público em geral:

A mídia também potencializa o caráter de performatividade das avaliações de larga escala, no contexto do Estado avaliador, na medida em que torna público e, portanto, relevante, os índices e indicadores de escolas e sistemas de ensino, focalizando a competição e o desempenho como parâmetros de qualidade.

Há, por fim, um discurso patente que envolve a superação, o desafio, o altruísmo, e a meritocracia como forma de obter resultados desejáveis nas avaliações de larga escala, valorizando de sobremaneira os resultados conquistados em nível individual como elementos exemplares da postura que será necessária para vencer no Estado avaliador através dos critérios da performatividade. (ESQUINSANI, 2010, p. 137).

Em síntese, pode-se conceber que a "cultura avaliativa" atribui um papel central para a avaliação, fazendo com que orbitem em torno dela os demais processos educacionais e tornando tais processos invisíveis diante do reluzir dos índices numéricos. A "qualidade" na cultura avaliativa atrela-se ao esforço por bem contemplar as avaliações e atingir melhores índices numéricos, que supostamente seriam capazes de a traduzir.

\section{ACCOUNTABILITY, PRESTAÇÃO DE CONTAS, RESPONSABILIZAÇÃO}

Grande parte das experiências e práticas anteriormente descritas ganham legitimidade e pertinência ao serem atreladas a um suposto controle social dos resultados do serviço público, responsabilidade que cabe a instituições e gestores públicos em prestar contas à população acerca de seus deveres. Tais demandas remetem "[...] a necessidade da proteção dos direitos do cidadão contra os usos (e abusos) do poder pelo governo como um todo, ou 
de qualquer indivíduo investido em função pública" (CAMPOS, 1990, p. 33), bem como aos princípios da democracia e à transparência na gestão pública que lhe é peculiar, assim como à vigilância da população sobre as ações do Estado que, em condições ideais, deveria ocorrer. $\bigcirc$ conceito que contempla essa experiência é accountability, cuja tradução para o português poderia ser "prestação de contas", sendo seu efeito mais contundente aquilo que pode ser tomado como "responsabilização", mecanismo que, para além da avaliação, atribui consequências benéficas ou punitivas às pessoas ou instituições de acordo com os resultados apresentados.

As democracias contemporâneas urgem por formas de controle acerca da gestão pública que explicitem $~$ cumprimento ou não de suas obrigações, e, de acordo com Schedler (2004, p. 8), accountability, "expresa de manera nítida esta preocupación continua por controles y contrapesos, por la supervisión y la restricción del poder." Afirma ainda o autor, que essa forma de controle depende de um tripé básico: "La rendición de cuentas en política usualmente abarca las tres dimensiones -información, justificación y sanción." (SCHEDLER, 2004, p. 19). Perante essa última afirmação, pode-se antever o caráter incipiente da prestação de contas em Educação Básica no Brasil, dado que ele somente abarca a visibilidade (a informação) e seus efeitos.

Segundo Campos (1990), accountability seria não apenas um termo ainda não traduzido para o português nas décadas finais do século XX, mas efetivamente um conceito inexistente - no léxico e nas práticas de gestão pública de países como o Brasil, o que remete à necessidade de certa "maturidade política" das instituições e da própria população para estabelecê-la:

Uma sociedade precisa atingir um certo nível de organização de seus interesses públicos e privados, antes de tornar-se capaz de exercer controle sobre o Estado. A extensão, qualidade e força dos controles são consequência do fortalecimento da malha institucional da sociedade civil. À medida que os diferentes interesses se organizam, aumenta a possibilidade de os cidadãos exercerem o controle e cobrarem do governo aquilo a que têm direito. Um desses mecanismos de controle seria a participação da sociedade civil na avaliação das políticas públicas, fazendo recomendações a partir dessa avaliação. (CAMPOS, 1990, p. 35). 
Reforçando esse aspecto, pontua Arato (2002, p. 103) que "[... ] a précondição mais importante para que um sistema de accountability realmente funcione é a atividade dos cidadãos nos fóruns públicos democráticos e na sociedade civil." Em outros termos, o controle social dos resultados da gestão pública não opera pela sua simples exposição de índices numéricos, mas pelo efetivo debate e problematização destes, em espaços coletivos de exercício da cidadania democrática. Essa apreciação da gestão pública pela população teria nas avaliações formais um instrumento possível, entretanto elas não seriam o cerne do processo.

Quando essa questão adentra ao setor educacional, ampliam-se as críticas, dada a centralidade das avaliações discentes no processo, bem como a concepção, um tanto arbitrária, que iguala altos índices à qualidade educacional. Além disso, a responsabilização em Educação foi prontamente identificada com perspectivas privadas/gerencialistas de gestão, agindo de modo dissonante com as características de serviços educacionais públicos e suas obrigações na vida democrática. Nessa perspectiva, a "qualidade" tornouse uma ferramenta propulsora de reformas que afrontam a prática educacional, já que

[...] o discurso da qualidade foi (e continua a ser frequentemente) um discurso redutor quando se baseia apenas numa racionalidade instrumental que tende a sobrevalorizar indicadores e resultados quantificáveis sem levar em conta as políticas educacionais, os sujeitos e os respectivos processos e contextos educativos. (AFONSO, 2007, p. 18).

A qualidade (ou a não qualidade) do serviço público seria o argumento legitimador de uma ampla transformação:

A orientação ideológica das ações reformadoras propostas desde meados dos anos 1990 foram amparadas pelo argumento de combate à burocracia, morosidade e ineficiência dos serviços no setor público. A produtividade e a qualidade, significantes eufemísticos desta orientação, 
passaram a orientar as práticas educacionais, submetendoas a critérios quantitativos, indicadores e ranqueamentos. A avaliação e o desempenho constituíram-se como elementos centrais na reorientação das políticas. A melhoria da qualidade do serviço público constitui enunciado fundamental para legitimar adoção de práticas gerencialistas oriundas do setor privado. (PIOLLI; SILVA; HELOANI, 2015, p. 592, grifo do autor).

Ravich (2011) atribui à responsabilização uma série de problemas que vêm acometendo a Educação Pública norte-americana. Segundo a autora, para além do franco desmonte de escolas em decorrência de baixos índices em avaliações e do sofrimento profissional dos envolvidos, tem-se a efetiva fragilização da Educação enquanto serviço de caráter público enviesado por princípios democráticos, sendo que em seu lugar emerge um ethos competitivo e predatório, típico do setor privado. Além disso, estaria avançando uma notável precarização do currículo, já que este se vê alienado ao que será avaliado nos testes. A própria concepção de avaliação e de tratamento de seus resultados também implicaria riscos ao que é desejável no campo educacional:

Por isso, ao contrário do que, por vezes, nos fazem crer, a adopção de certos dispositivos de avaliação externa (sobretudo os que são exclusivamente baseados em indicadores quantificáveis e mensuráveis) não contribuirá para a tão propagandeada melhoria da qualidade do ensino, representando antes um retrocesso político e educacional injustificável quando comparado com os progressos científicos e epistemológicos que têm vindo a conduzir a avaliação para perspectivas anti-positivistas, mais complexas, pluralistas, democráticas e objectivas. (AFONSO, 2007, p. 20).

Quanto à realidade nacional, embora a comparação ou a concorrência entre instituições e sistemas não seja a intenção explícita das avaliações dirigidas à Educação Básica brasileira, não raras vezes, isso efetivamente ocorre, seja em comparações informais, seja em releituras midiáticas sobre o tema, gerando a tensão política e subjetiva típica de estados de concorrência. $\bigcirc$ princípio da transparência, desejável nas democracias, acaba por ser subvertido, restando dele um espetaculoso efeito de visibilidade, que contempla um resultado 
final determinado pela análise arbitrária de alguns poucos indicadores e não o processo educacional como um todo. A responsabilização rapidamente converte-se em pressão por resultados. $\bigcirc$ número resultante da avaliação, como, por exemplo, o Índice de Desenvolvimento da Educação Básica (Ideb), torna-se o objeto visível gerador de discursos. Seu número, seus gráficos, suas comparações e metas, quando expostas de modo direto e acrítico, ou quando inseridos em um discurso politicamente enviesado, permitem apressadas conclusões sobre as instituições avaliadas e sobre as pessoas que ali estudam ou trabalham. Ball (2005, p. 546-547) alerta para alguns dos desdobramentos práticos de mecanismo dessa natureza:

Novos papéis e subjetividades são produzidos à medida que os professores são transformados em produtores/ fornecedores, empresários da educação e administradores, e ficam sujeitos à avaliação e análise periódicas e a comparações de desempenho. Novas formas de disciplina são instituídas pela competição, eficiência e produtividade. E novos sistemas éticos são introduzidos, com base no interesse próprio da instituição, no pragmatismo e no valor performativo.

Sob a bandeira da responsabilização e da transparência, ocorre a inserção de novos dispositivos disciplinares, fenômeno que, com maior ou menor intensidade, vem ocorrendo em vários países. Mecanismos de avaliação externa periódica proporcionam novas possibilidades de controle da ação dos sujeitos e ajustamento de suas subjetividades. Conforme Ball (2002, p. 7), "[...] as tecnologias têm seu papel em 'caracterizar-nos' de forma diferente do que éramos, fornecendo novos modos de descrição para o que fazemos e novas possibilidades de ação." Por trás de uma aparente objetividade, a responsabilização performaticamente enviesada "[...] coloca em pauta uma dimensão emocional" (BALL, 2005, p. 550), forjando sujeitos e práticas que deem conta de expectativas externas à área educacional e às suas instituições.

Embora haja na accountability o potencial de se realizar um desejável monitoramento dos serviços de caráter público, tanto para o Estado quanto para a população, "[...] resulta questionável a associação entre melhoria da qualidade educacional e a adoção de ferramentas de accountability na forma 
como esta vem sendo concebida pelos produtores das políticas avaliativas nas últimas décadas." (SCHNEIDER; NARDI, 2015, p. 68). Nota-se, como apontado por Afonso (2007), dentre diversos pontos contestáveis, a ausência de avaliações acerca das políticas educacionais adotadas, tópico sumamente importante na condução da Educação pública, mas que tem sido ofuscado pela centralidade na avaliação do desempenho discente:

\begin{abstract}
$\bigcirc$ acesso às informações que devem ser disponibilizadas pelos processos de avaliação é uma prerrogativa legítima dos cidadãos e do próprio Estado democrático, em favor do incremento da participação cívica e educacional, e em congruência com a transparência e a responsabilização. Também, por isso, é absolutamente necessário que as próprias políticas públicas educacionais sejam avaliadas. Mas a avaliação das políticas, nos campos da educação e da formação, não pode circunscrever-se à avaliação dos alunos ou à avaliação das aprendizagens (como também não é nem pode ser, isoladamente ou mesmo de forma conjugada, avaliação dos professores ou avaliação das escolas). A avaliação dos sistemas educativos pode, em alguns casos, ser a avaliação conjugada de alunos, professores e escolas, mas, mesmo assim, não coincide necessariamente com a avaliação de políticas, ainda que a interface seja relativamente óbvia. A avaliação das políticas (sobretudo em contextos macro e mega) implica, entre muitas outras dimensões, conhecer os processos de génese, desenvolvimento e decisão política; pressupõe uma análise dos factores relacionados com a natureza política do Estado, a sua maior ou menor autonomia relativa, a evolução e as implicações dos processos de globalização e transnacionalização, os (novos) processos de regulação, as reconfigurações e as lógicas de mediação Estado, mercado, terceiro sector, entre muitos outros aspectos. Neste sentido, apesar da insistência frequente na necessidade de uma cultura de avaliação, a avaliação das políticas está consideravelmente menos teorizada (e menos valorizada) e é menos praticada do que a avaliação dos alunos, das escolas e dos professores. (AFONSO, 2007, p. 19)
\end{abstract}

Nesse enredo, o indicador numérico resultante do desempenho cognitivo de alunos materializa e evidencia a dignidade de uma complexa prática, podendo, então, tornar-se o objetivo primordial do processo empreendido. $\bigcirc$ controle da sociedade sobre serviços públicos é uma necessidade óbvia; entretanto, ao menos no campo educacional, os meios 
pelos quais tal controle vem sendo conduzido indicam a possibilidade de uma efetiva alienação da Educação a uma perspectiva análise francamente limitada, mas politicamente poderosa.

\section{CONCLUSÃO: A EMERGÊNCIA DE UMA QUALIDADE NOS JOGOS DE UERDADE CONTEMPORÂNEOS}

Tomando as considerações anteriormente expostas, pode-se inferir que a aparição da qualidade educacional enquanto performance em testes padronizados se institui dentro de uma rede discursiva heterogênea, mas com fortes pontos de coesão. Essa qualidade não é um objeto isolado, pertencente aos limites do discurso político-educacional ou pedagógico, antes, trama-se a estes, ancorada por discursos oriundos do campo econômico, da política e da cultura performática. Entretanto, não se pode afirmar que se trata de uma construção de objeto totalmente enxertada à Educação, dado que os meios e as formas pelas quais esse objeto é capturado ou instituído remetem a práticas típicas das instituições educacionais modernas - o exame, as notas, as médias "aceitáveis", etc. Recapitulando os aspectos mais pertinentes do quadro discursivo contemporâneo que dão ao discurso da qualidade em tela suas condições de possibilidade, pode-se relacionar os seguintes pontos de interdiscursividade: a) a perspectiva de mercado, ou o gerencialismo, que salienta a necessidade de uma gestão focada na eficiência e eficácia dos processos e a redução de custos daí proveniente, condição inevitável para a sobrevivência das organizações privadas no mercado globalizado; b) a performatividade, que, já há cerca de quatro décadas, vem sendo reconhecida como um crivo de validação da experiência, um modo de legitimar, comparar e pôr em concorrência pessoas, instituições e governos (LYOTARD, 2000), operando para além da objetividade dos números - inscrevendo-se na subjetividade dos envolvidos como um potente elemento motivador; c) a cultura avaliativa, que institui a avaliação como uma meta e não como um recurso de constatação, tornando o teste o eixo de processos que deveriam abarcar outras prioridades efetivamente "naturais" a eles e não esse elemento estranho ao empreendimento, como uma avaliação 
externa; d) a responsabilização, que tem o potencial de revestir fortes (e por vezes violentas) investidas sobre pessoas e instituições, de ideais de justiça e democracia, convertendo o pertinente controle social do emprego dos recursos públicos em um evento teatral que viabiliza tomadas de decisões irrefletidas acerca de serviços e instituições públicas.

Tais discursos são, a princípio, "isoláveis" somente em uma explanação conceitual e didática. Nota-se que é na coexistência deles que emerge o potencial político que lhes é peculiar, bem como a dimensão de sentido que possuem, ou seja, suas existências como instrumentos de poder e recursos do saber, viabilizam-se por meio de sua concomitância.

A fabricação do objeto qualidade educacional enquanto performance em testes padronizados remete a esse campo interdiscursivo, cujos enunciados proporcionam a ele pontos de ancoragem e minimizam ou ofuscam suas inconsistências. Como produto da contemporaneidade, tal objeto seria francamente impossível fora do contexto presente: ele seria desnecessário, política ou epistemicamente infrutífero, cientificamente inconsistente. $\bigcirc$ "conforto" dessa rede discursiva, entretanto, não livra a questão do embate típico de qualquer obra do discurso, sendo que o presente debate, intenta problematizar o estatuto de verdade dessa qualidade.

\section{REFERÊNCIAS}

ABRUCIO, F. L. O impacto do modelo gerencial na Administração Pública: um breve estudo sobre a experiência internacional recente. Cadernos ENAP, Brasília, DF, n. 10, 1997.

AFONSO, A. J. Estado, políticas educacionais e obsessão avaliativa. Contrapontos, Itajaí, v. 7, n. 1, p. 11-22, jan./abr. 2007.

AFONSO, A. J. Reforma do Estado e políticas educacionais: entre a crise do Estado-nação e a emergência da regulação supranacional. Educação \& Sociedade, Campinas, v. 22. n. 75, p. 15-32, ago. 2001.

ANDRADE, E. C. Rankings em educação: tipos, problemas, informações e mudanças. Estudos Econômicos, São Paulo, v. 4l, n. 2, jun. 2011. 
ARATO, A. Representação, soberania popular, e accountability. Lua Nova, São Paulo, n. 55-56, p. 85-103, 2002.

BALL, S. J. Performatividade, privatização e o pós-Estado do Bem-Estar. Educação e Sociedade, Campinas, v. 25, n. 89, dez. 2004.

BALL, S. J. Performatividades e fabricações na economia educacional: rumo a uma sociedade performativa. Educação \& Realidade, n. 35, v. 2, p. 37-55, maio/ago. 2010.

BALL, S. J. Profissionalismo, gerencialismo e performatividade. Cadernos de Pesquisa, São Paulo, v. 35, n. 126, set./dez. 2005.

BALL, S. J. Reformar escolas/reformar professores e os terrores da performatividade. Revista Portuguesa de Educação, Minho, v. 15, n. 2, 2002.

BRASIL. Ministério da Educação. Portaria n. 931, de 21 de março de 2005. Diário Oficial da União, Brasília, DF, 22 mar. 2005. Disponível em: <http:// download.inep.gov.br/educacao_basica/prova_brasil_saeb/downloads/ Port931_21MAR05.pdf>. Acesso em: 02 nov. $2 \overline{0} 17$.

CAMPOS, A. M. Accounstability: quando poderemos traduzi-la para o português? Revista de Administração Pública, Rio de Janeiro, v. 24, n. 2, p. 30-50, 1990.

DAMETTO, J.; ESQUINSANI, R. S. S. Avaliação educacional em larga escala: performatividade e perversão da experiência educacional. Educação, Santa Maria, p. 619-630, set. 2015. Disponível em: <https://periodicos.ufsm.br/reveducacao/article/view/13742>. Acesso em: 10 maio 2018. doi:http://dx.doi. org/10.5902/1984644413742.

DOURADO, L. F; OlIVEIRA, J. F. de. SANTOS, C. de A. A qualidade da Educação: conceitos e definições. Brasília, DF: MEC/INEP, 2007.

ESQUINSANI, R. S. S. Performatividade e educação: a política das avaliações em larga escala e a apropriação da mídia. Práxis Educativa, Ponta Grossa, v. 5, n. 2, p. 131-137, jul./dez. 2010.

FISCHER, R. M. B. Foucault e a análise do discurso em educação. Cadernos de Pesquisa, São Paulo, n. 114, p. 197-223, nov. 2001.

FOUCAULT, M. A arqueologia do saber. 7. ed. Rio de Janeiro: Forense Universitária, 2008a. 
FOUCAULT, M. Nascimento da biopolítica. São Paulo: Martins Fontes, 2008b.

GUIA DO ESTUDANTE. Entenda a avaliação de cursos 2016 do Guia do Estudante. 16 maio 2016. Disponível em: <http://guiadoestudante.abril.com.br/universidades/entenda-como-e-feita-a-avaliacao-de-cursos-do-guia-do-estudante/>. Acesso em: 20 maio 2018.

ICLE, G. Para apresentar a performance à Educação. Educação \& Realidade, v. 35, n. 2, p. 11-22, maio/ago. 2010.

LYOTARD, J.-F. A condição pós-moderna. 6. ed. Rio de Janeiro: José Olympo, 2000.

MONTEIRO, G. C. M.; FERNANDES, T. W. de P. O SAEB e seus enfoques: tecendo algumas considerações. In: Educação e qualidade: sistemas educacionais em construção. Juiz de Fora: Ed. UFJF, 2012. p. 95-112.

MORRIS, P. Política educacional, exames internacionais de desempenho e a busca da escolarização de classe mundial: uma análise crítica. Estudos em Avaliação Educacional, São Paulo, v. 28, n. 68, p. 302-342, maio/ago. 2017. Disponível em: <http://publicacoes.fcc.org.br/ojs/index.php/eae/article/ view/4696/3379>. Acesso em: 20 maio 2018.

PIOLLI, E.; SILVA, E. P.; HELOANI, J. R. M. Plano Nacional de Educação, autonomia controlada e adoecimento do professor. Cadernos CEDES, Campinas, v. 35, n. 97, p. 589-607, dez. 2015.

RAMOS, G. P. Racionalidade e gerencialismo na política educacional paulista de 1995 a 2014: muito além das conjunturas. Ensaio: avaliação e políticas públicas em Educação, Rio de Janeiro, v. 24, n. 92, p. 546-578, set. 2016.

RAVITCH, D. Vida e morte do grande sistema escolar americano: como os testes padronizados e o modelo de mercado ameaçam a educação. Porto Alegre: Sulina, 2011.

ROSISTOLATO, R.; PRADO, A. P. do; FERNÁNDEZ, S. J. Cobranças, estratégias e "jeitinhos": avaliações em larga escala no Rio de Janeiro. Estudos em Avaliação Educacional, São Paulo, v. 25, n. 59, p. 78-107, maio/ago. 2014. Disponível em: <http://publicacoes.fcc.org.br/ojs/index.php/eae/article/ view/2853/2850>. Acesso em: 20 maio 2018.

SANTOS, L. L. C. P. Formação de professores na cultura do desempenho.

Educação e Sociedade, Campinas, v. 25, n. 89, dez. 2004. 
SCHEDLER, A. ¿Qué es la rendición de cuentas? Cuadernos de Transparência, IFAI, México, n. 3, 2004. 48 p.

SCHNEIDER, M. P.; NARDI, E. L. Accountability em educação: mais regulação da qualidade ou apenas um estágio do Estado-avaliador? ETD - Educação Temática Digital, Campinas, v. 17, n. 1, p. 58-74, jan./abr. 2015.

SHIROMA, E. O. Performatividade e intensificação: tendências para o sistema de formação docente. In: CENCI, Â. V.; DALBOSCO, C. A.; MÜHL, E. H. (Org.). Sobre filosofia e educação: racionalidade, diversidade e formação pedagógica. Passo Fundo: Ed. UPF, 2009. p. 374-387.

Recebido em 30 de janeiro de 2018 Aceito em 08 de junho de 2018

Endereços para correspondência: Jarbas Dametto - Rua Narciso Sebben, 282, apto. 302, Centro, 99950-000, Tapejara, Rio Grande do Sul, Brasil; jarbas@ upf.br 